\title{
Synthesis of Poly(vinyl alcohol) Graft Copolymers by Living Cationic Polymerization in the Presence of Added Bases I. Design and Synthesis of Poly(vinyl alcohol) Graft Copolymers with Well-Controlled Poly(vinyl ether) Grafts
}

\author{
Sadahito Aoshima, ${ }^{\dagger}$ Masakuni IkedA, ${ }^{*}$ Koji NaKayama, ${ }^{*}$ Eiichi Kobayashi, $,{ }^{*}, \dagger$ \\ Hiroyuki OHGI, ${ }^{* *}$ and Toshiaki SATO** \\ Department of Macromolecular Science, Graduate School of Science, Osaka University, \\ Toyonaka, Osaka 560-0043, Japan \\ ${ }^{*}$ Department of Industrial Chemistry, Faculty of Science and Technology, Science University of Tokyo, \\ Noda, Chiba 278-8510, Japan \\ ${ }^{* *}$ Kuraray Co., Kurashiki, Okayama 710-0801, Japan
}

(Received March 22, 2001; Accepted June 15, 2001)

\begin{abstract}
A new method of synthesis of Poly(vinyl alcohol) (PVA) graft copolymers via living cationic polymerization was designed using a new coupling reagent, partially-hydrolyzed poly(vinyl acetate) (PVAc-OH). The living cationic polymerization of vinyl ethers was carried out in the presence of added bases, and the living propagating species were allowed to react with PVAc-OH, selectively. The graft copolymers contained well-controlled poly(vinyl ether) grafts with a very narrow molecular weight distribution. The PVAc main chain was quantitatively converted to PVA by hydrolysis under mild alkaline conditions. The resulting PVA graft copolymers could dissolve in not only water and DMSO, but also many organic solvents such as toluene and chloroform. The graft copolymers with poly(2-methoxyethyl vinyl ether) and/or poly(2-ethoxyethyl vinyl ether) turned out to exhibit the unique behavior of thermosensitive phase separation in water. When the aqueous solution was warmed to the critical temperature, the clear solution changed to opaque in a rapid transition. On the other hand, at below room temperature, characteristic physical gelation of main chain PVA was also observed gradually.

KEY WORDS Synthesis of Poly(vinyl alcohol) (PVA) Graft Copolymer / Living Cationic Polymerization / Vinyl Ether / Partially-Hydrolyzed Poly(vinyl acetate) / "Grafting onto" Method / WellControlled Graft / Thermosensitive Solution Property /
\end{abstract}

The development of novel advanced water-soluble polymers of various shapes and characteristic properties has attracted a lot of attention from both scientific and industrial fields. Recent progress in living polymerization, in particular, has advanced the novel design and syntheses of such water-soluble block or graft copolymers. ${ }^{1-5}$ However, the design of welldefined poly(vinyl alcohol) (PVA)-based copolymers has been limited due to difficulties in the living (radical) polymerization of vinyl acetate $e^{6-8}$ and its poor copolymerizability. In particular, for PVA-based graft copolymers with well-defined segments, in spite of their potential for practical application, there are only limited examples, realized by relatively cumbersome "macromonomer" methods. ${ }^{9-13}$

Recently, on the basis of stabilization of the propagating carbocations via the nucleophilic interaction of externally-added bases, we have achieved the living cationic polymerization of vinyl ethers, ${ }^{14-16}$ giving not only poly(vinyl ether)s with a quite narrow molecular weight distribution (MWD), but also various am-

\footnotetext{
${ }^{\dagger}$ To whom correspondence should be addressed.

${ }^{\dagger}$ Deceased.
}

phiphilic block copolymers. For example, amphiphilic block copolymers having stimuli-responsive segments have been found to exhibit selective thermal gelation. ${ }^{17,18}$ In the present paper, in order to extend the applicability of the living cationic polymerization system to the new polymer architecture, we designed a new method of synthesis and prepared a new series of welldefined PVA graft copolymers.

\section{Principle of Synthesis of PVA Graft Copolymers via} Living Cationic Polymerization

Scheme 1 shows the strategy for preparing PVA graft copolymers with various well-controlled poly(vinyl ether) grafts, falling under the category of "grafting onto" methods. ${ }^{19}$ The synthesis involves the living cationic polymerization of vinyl ethers and subsequent coupling (termination) reaction with partiallyhydrolyzed poly(vinyl acetate) (PVAc-OH). Thus, if the polymerization of vinyl ethers can proceed in living fashion and the propagating species be allowed to react selectively with PVAc-OH, graft copolymers with well-controlled poly(vinyl ether) grafts can be obtained in quantitative yield without the production of 
Synthesis of PVA Graft Copolymers by Living Cationic Polymn

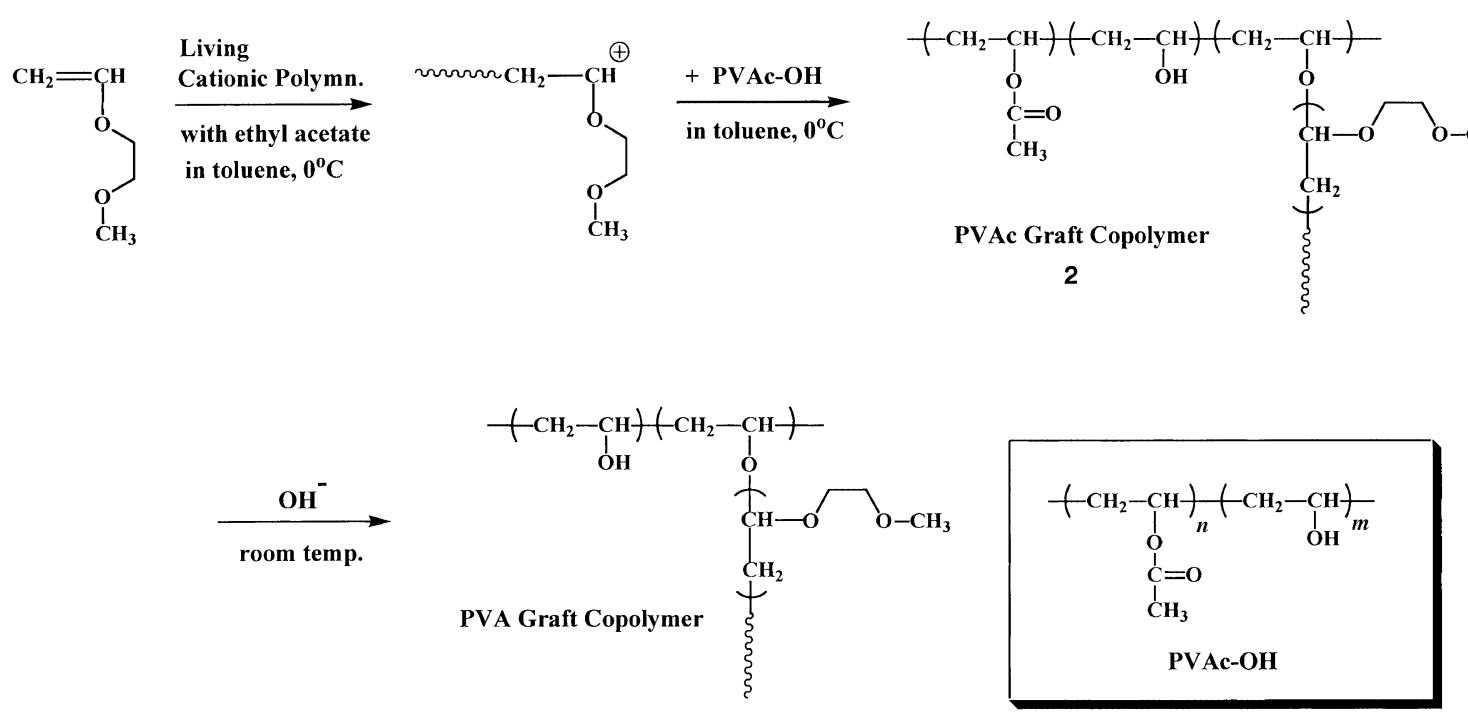

Scheme 1. A synthetic route of PVA graft copolymers via living cationic polymerization.

homopolymer by-products. The most characteristic features of this procedure are (i) the use of new reactive polymers with many hydroxy groups as a coupling agent that is soluble in several organic solvents, (ii) the possibility of preparing graft copolymers with well-controlled grafts in good yield compared to polymer reaction using non-ionic compounds, and (iii) the ready conversion of the main chain to PVA by conventional base-promoted hydrolysis.

The present paper describes the preliminary results of the synthesis of PVA graft copolymers having wellcontrolled poly(vinyl ether)s, based on the strategy outlined above. This strategy is potentially applicable to cationically polymerizable monomers such as vinyl ethers $^{20}$ and styrenes. ${ }^{21}$

\section{EXPERIMENTAL}

\section{Materials}

2-Butoxyethyl vinyl ether (BOVE) was prepared from 2-hyoxyethyl vinyl ether (BASF Japan), $\mathrm{NaH}$, and butyl iodide in 1,4-dioxane at $80^{\circ} \mathrm{C}$ for $10 \mathrm{~h}$ (yield $80 \%$, bp: $78^{\circ} \mathrm{C} / 35 \mathrm{mmHg}$ ). The monomers, BOVE, 2-methoxyethyl vinyl ether (MOVE, Nisso Maruzen Chemical), 2-ethoxyethyl vinyl ether (EOVE, Nisso Maruzen Chemical), and isobutyl vinyl ether (IBVE, Tokyo Kasei) were distilled twice over calcium hydride before use. $\mathrm{Et}_{1.5} \mathrm{AlCl}_{1.5}$ (Nippon Alkyl Aluminum) was distilled under reduced pressure. Solvents (toluene, hexane) and an added base (ethyl acetate) were purified by the usual method and distilled at least twice over calcium hydride just before use. ${ }^{14}$ As a cationogen, 1-(isobutoxy)ethyl acetate $\mathrm{CH}_{3} \mathrm{CH}(\mathrm{O} i \mathrm{Bu}) \mathrm{OCOCH}_{3}$ (1) was prepared by treatment of IBVE with acetic acid at $60^{\circ} \mathrm{C}$ for $3 \mathrm{~h}$, and distilled over calcium hydride under reduced pressure. ${ }^{14}$

Synthesis of Graft Copolymers: Living Cationic Polymerization and Coupling Reactions

Partially-hydrolyzed PVAc (PVAc-OH: $\overline{\mathrm{DP}}_{\mathrm{n}}=180$ or $500, m /(n+m)=0.1$ or 0.2 , atactic; provided by Kuraray Co.) was purified by column chromatography and freeze-dried from benzene solution. Benzene solvent for freeze-drying was distilled twice over calcium hydride.

For the preparation of side grafts, the living cationic polymerization of MOVE was carried out at $0^{\circ} \mathrm{C}$ in a baked glass tube equipped with a three-way stopcock under a dry nitrogen atmosphere. ${ }^{14-16}$ The reaction was initiated by adding an initiator solution $\left(\mathrm{Et}_{1.5} \mathrm{AlCl}_{1.5}\right.$ in hexane) to a mixture of a monomer, an added base, the cationogen 1 , and a solvent at $0^{\circ} \mathrm{C}$ using a dry medical syringe. In the case of MOVE-EOVE block copolymerization, after MOVE was polymerized, the second monomer, EOVE (neat), was added into the glass tube at the same temperature. After a certain period, $\mathrm{PVAc}-\mathrm{OH}$ in toluene was added to the polymerization mixture at $0^{\circ} \mathrm{C}$ by a medical syringe. After the addition of methanol, the reaction mixture was diluted with dichloromethane, and then washed with water to remove the initiator residues. The graft copolymers were recovered from the organic layer by evaporation of the solvents under reduced pressure and vacuum dried overnight. The graft efficiency and MWD of the products were determined by SEC measurement.

For the model of side grafts, the polymerization of vinyl ethers was also quenched with prechilled $0.3 \mathrm{wt} \%$ ammoniac methanol. The quenched reaction mixture was diluted with dichloromethane, and then washed with $0.6 \mathrm{~N}$ hydrochloric acid to remove the initiator 
residues, and neutralized. The product polymer was recovered from the organic layer by evaporation of the solvents under reduced pressure and vacuum dried overnight. The conversion of the monomer was measured by gravimetry.

The graft copolymer was hydrolyzed in $1 \mathrm{wt} \% \mathrm{NaOH}$ aq-methanol solution at room temperature for $24 \mathrm{~h}$ and the backbone could be exchanged to PVA almost quantitatively. The organic solution was concentrated by evaporation to a few milliliters. The concentrated solution was poured into a large amount of aqueous methanol $(c a .2 \%(\mathrm{v} / \mathrm{v})$ water) to remove sodium acetate etc. and the precipitated polymer was separated by decantation. The purification procedure was repeated several times. The graft copolymers were then vacuum dried overnight at room temperature. The progress of hydrolysis was confirmed by ${ }^{1} \mathrm{H}$ NMR [JEOL EX400 (400 MHz)].

\section{Polymer Characterization}

The MWDs of poly(vinyl ether)s and graft copolymers were determined by size exclusion chromatography (SEC) in chloroform at $40^{\circ} \mathrm{C}$ on a Tosoh CCPD chromatograph equipped with three polystyrene gel columns [TSK gel G-2000, 3000, and 4000; $8.0 \mathrm{~mm}$ (i.d.) $\times 300 \mathrm{~mm}$ each] and a refractive index detector. The number-average molecular weight $\left(\bar{M}_{\mathrm{n}}\right), \bar{M}_{\mathrm{w}} / \bar{M}_{\mathrm{n}}$, and the graft efficiency were calculated from SEC curves on the basis of a polystyrene calibration. The structure of graft copolymers was determined by ${ }^{1} \mathrm{H}$ NMR and IR [JASCO FT/IR-410] spectroscopy.

\section{RESULTS AND DISCUSSION}

Synthesis of PVAc Graft Copolymers: Living Cationic Polymerization and Coupling Reactions

As a new coupling agent with many hydroxy groups, we employed partially hydrolyzed poly(vinyl acetate) (PVAc-OH: $\overline{\mathrm{DP}}_{\mathrm{n}}=180$ or $500, m /(n+m)=0.1$ or 0.2 , atactic). In spite of such a structure having many hydroxyl groups, PVAc-OHs with low hydrolysis ratios $(\leq 20 \%)$ were found to be soluble in several organic solvents, such as toluene and chloroform.

Living propagating carbocations of poly(MOVE) were synthesized by cationic polymerization of MOVE in the presence of ethyl acetate by $1 / \mathrm{Et}_{1.5} \mathrm{AlCl}_{1.5}$ in toluene at $0^{\circ} \mathrm{C}^{14-16} \mathrm{In}$ separate experiments using methanol as a coupling (terminating) agent (Figure 1), the formation of poly(MOVE) with narrow MWD $\left(\bar{M}_{\mathrm{n}}=7.4 \times 10^{3}, \bar{M}_{\mathrm{w}} / \bar{M}_{\mathrm{n}}=1.1-1.2\right)$ was confirmed under the same conditions and at the same degree of monomer conversion. As shown in Figure 1, the PVAc$\mathrm{OH}$ solution was added to the polymerization mixture

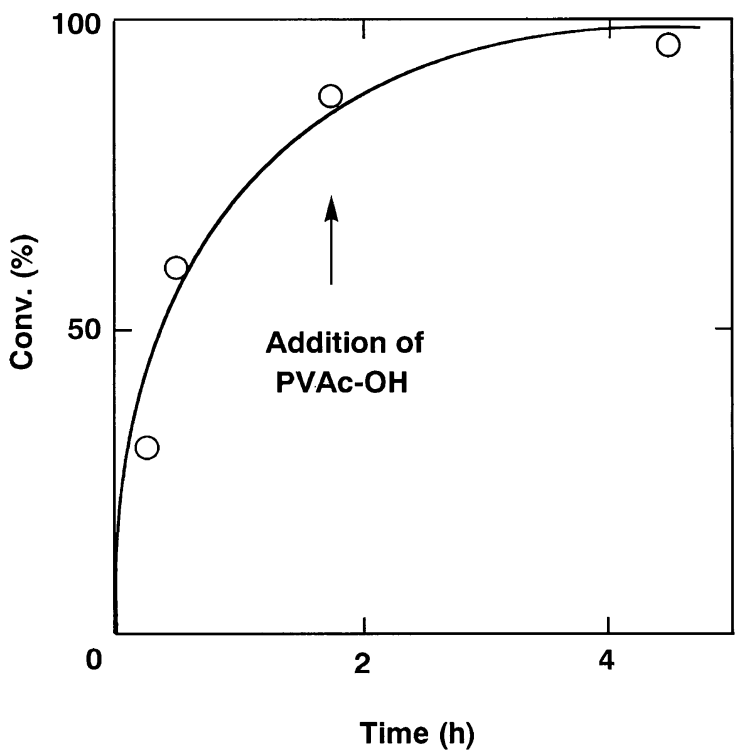

Figure 1. Time-conversion curve for polymerization of MOVE by $1 / \mathrm{Et}_{1.5} \mathrm{AlCl}_{1.5}$ initiating system in the presence of ethyl acetate in toluene at $0^{\circ} \mathrm{C}$. For the synthesis of graft copolymers, the $\mathrm{PVAc}-\mathrm{OH}$ solution was added to the polymerization mixture at the time indicated by the arrow: $[\mathrm{MOVE}]_{0}=0.44 \mathrm{M},[1]_{0}=4.0 \mathrm{mM}$, $\left[\mathrm{Et}_{1.5} \mathrm{AlCl}_{1.5}\right]_{0}=20 \mathrm{mM}$, [ethyl acetate] $=1.0 \mathrm{M}$.

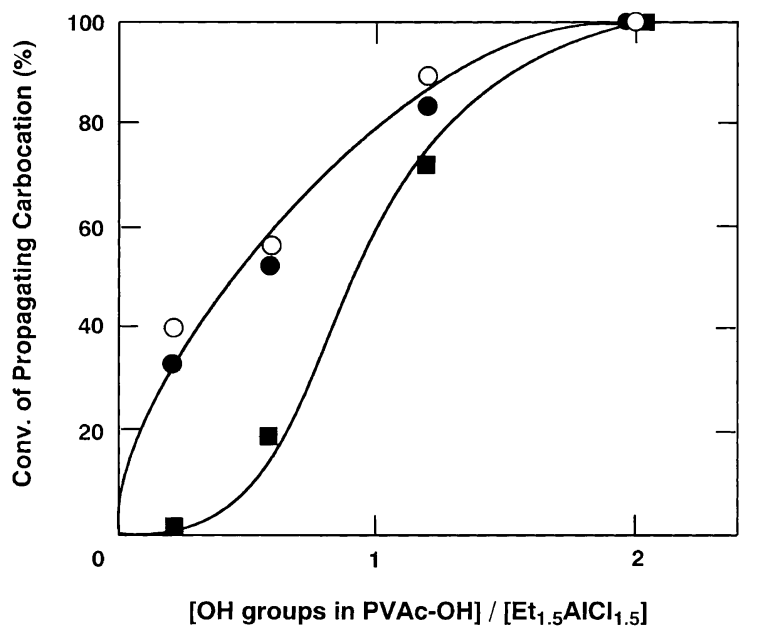

Figure 2. Relationships between [OH groups in PVAc-OH] / $\left[\mathrm{Et}_{1.5} \mathrm{AlCl}_{1.5}\right]$ and conversion of the propagating species obtained by polymerization of MOVE with $1 / \mathrm{Et}_{1.5} \mathrm{AlCl}_{1.5}$ initiating system in the presence of ethyl acetate in toluene at $0^{\circ} \mathrm{C}$. PVAc$\mathrm{OH}:(\bigcirc) \overline{\mathrm{DP}}_{\mathrm{n}}=180, \mathrm{~m} /(\mathrm{n}+\mathrm{m})=0.1 ;(\mathbf{O}) 180,0.2 ;$ (口) 500, 0.1: $[\mathrm{MOVE}]_{0}=0.44 \mathrm{M},[\mathbf{1}]_{0}=4.0 \mathrm{mM},\left[\mathrm{Et}_{1.5} \mathrm{AlCl}_{1.5}\right]_{0}=20 \mathrm{mM}$, [ethyl acetate $]=1.0 \mathrm{M}$.

at $88 \%$ conversion using a medical syringe. In the course of the coupling reaction, no side reactions relating to $\mathrm{PVAc}-\mathrm{OH}$ occurred, such as complex formation with $\mathrm{Et}_{1.5} \mathrm{AlCl}_{1.5}$. The graft copolymers were recovered from the organic layer by evaporation of the solvents under reduced pressure and then vacuum dried overnight. During the working-up procedure, it was necessary to maintain conditions to avoid the acidic hydrolysis of acetal bonds in the products. 
(A)

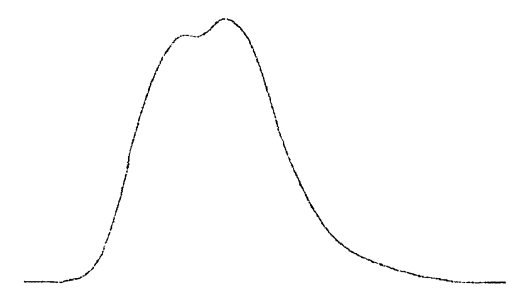

(B)

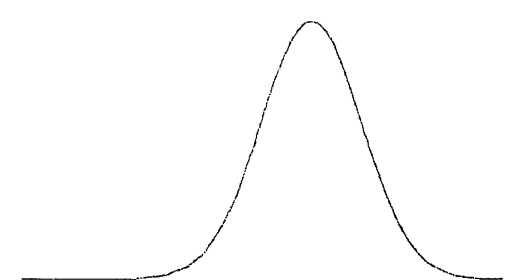

(C)

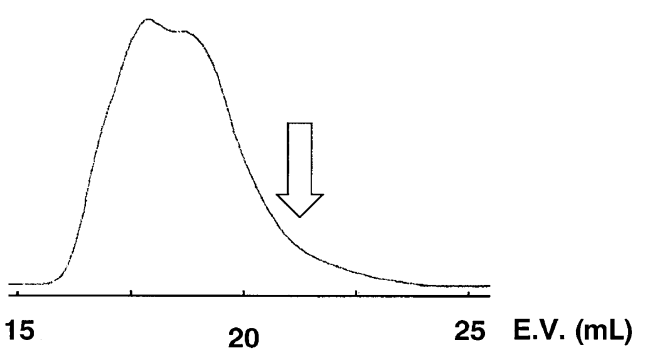

Figure 3. Molecular weight distributions of (A) $\mathrm{PVAc}-\mathrm{OH}$, (B) poly(MOVE), and (C) PVAc graft copolymer. (A) $\overline{\mathrm{DP}}_{\mathrm{n}}=500$, $m /(n+m)=0.1, \bar{M}_{\mathrm{n}}=4.2 \times 10^{4}, \bar{M}_{\mathrm{w}} / \bar{M}_{\mathrm{n}}=2.3 ;$ (B) $\bar{M}_{\mathrm{n}}=7.4$ $\times 10^{3}, \bar{M}_{\mathrm{w}} / \bar{M}_{\mathrm{n}}=1.2 ;(\mathrm{C}) \bar{M}_{\mathrm{n}}=5.8 \times 10^{4}, \bar{M}_{\mathrm{w}} / \bar{M}_{\mathrm{n}}=1.8$. The arrow indicates the position of the peak for homopoly(MOVE).

The effect of the total amounts of $\mathrm{OH}$ groups in PVAc-OH on graft efficiency was examined in order to identify the optimum conditions for the coupling reactions. Figure 2 shows the relationship between conversion of the propagating carbocations (graft efficiency) and the ratio of total $\mathrm{OH}$ abundance in PVAc-OH to that of the propagating species $\left(\mathrm{Et}_{1.5} \mathrm{AlCl}_{1.5}\right)$. The graft efficiency and MWD of the products were determined by ${ }^{1} \mathrm{H}$ NMR and SEC measurements. The graft efficiency was found to clearly depend on the number of $\mathrm{OH}$ groups in PVAc-OH. Under the conditions of $[\mathrm{OH}$ in PVAc-OH] $]\left[\mathrm{Et}_{1.5} \mathrm{AlCl}_{1.5}\right] \geq 2$, the coupling reaction occurred quantitatively, affording graft copolymers without homopoly(MOVE) by-products, regardless of the difference in $\overline{\mathrm{DP}}_{\mathrm{n}}$ and the hydrolysis ratio $[m /(n+m)]$ of PVAc-OH. Figure 3 shows a typical MWD of the graft copolymer thus obtained. The quantitative formation of graft copolymers was confirmed by the absence of a homopoly(MOVE) peak for $21.2 \mathrm{~mL}$ elution volume and in separate experiments involving extraction by water. The MWD of the product polymer shifted somewhat toward higher molecular weights, where the unexpected small shift was thought to be due to the compact structure of graft copolymers in solution. Figure 4 shows the ${ }^{1} \mathrm{H}$ NMR spectra of the starting polymers, PVAc-OH and poly(MOVE), and the product copolymer obtained after the coupling re-

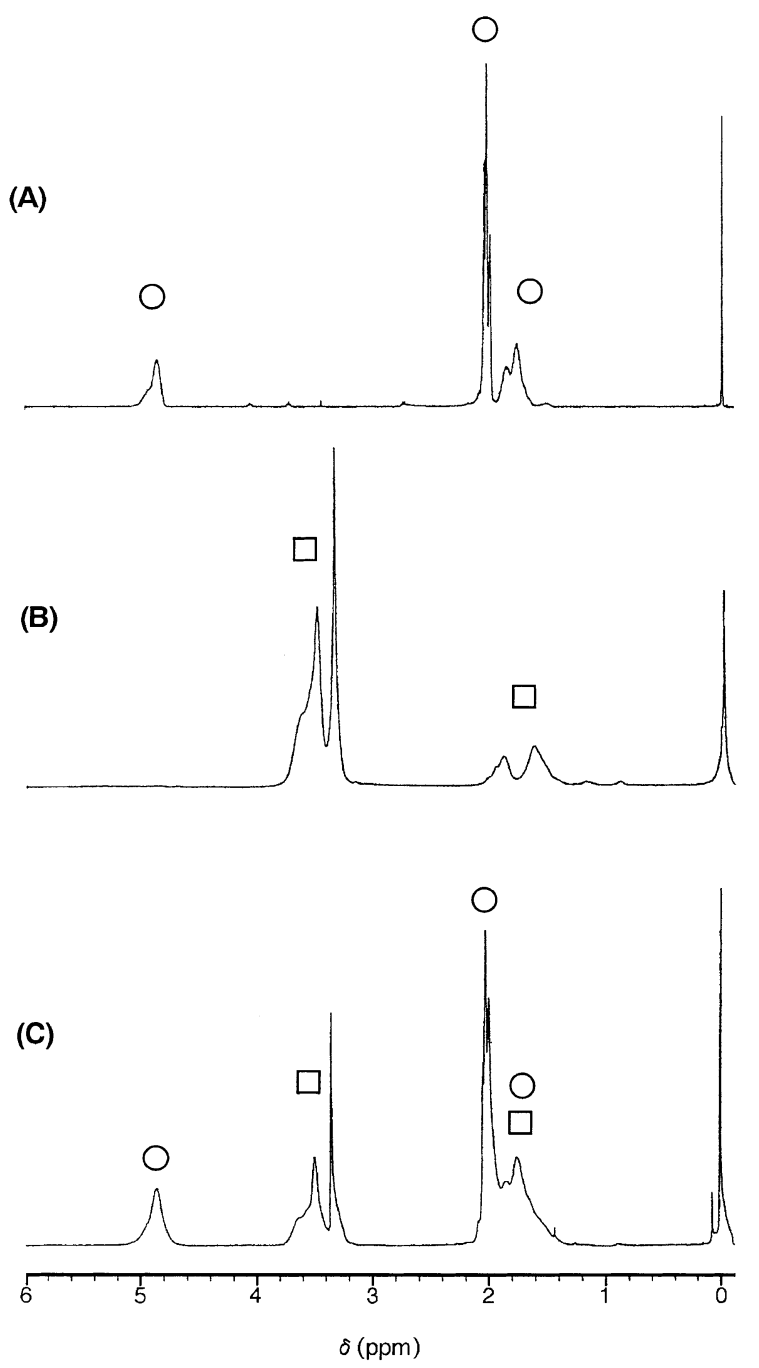

Figure 4. ${ }^{1} \mathrm{H}$ NMR Spectra of (A) PVAc-OH, (B) poly(MOVE), and (C) PVAc graft copolymer (in $\mathrm{CDCl}_{3}, 27^{\circ} \mathrm{C}$ ). (A) $\overline{\mathrm{DP}}_{\mathrm{n}}=500, m /(n+m)=0.1, \bar{M}_{\mathrm{n}}=4.2 \times 10^{4}, \bar{M}_{\mathrm{w}} / \bar{M}_{\mathrm{n}}=2.3 ;$ (B) $\bar{M}_{\mathrm{n}}=7.4 \times 10^{3}, \bar{M}_{\mathrm{w}} / \bar{M}_{\mathrm{n}}=1.2 ;(\mathrm{C}) \bar{M}_{\mathrm{n}}=5.8 \times 10^{4}, \bar{M}_{\mathrm{w}} / \bar{M}_{\mathrm{n}}=1.8$.

action. A comparison of each spectrum in Figure 4 reveals that the spectrum of the graft copolymer contains signals due to both the main chain PVAc-OH and the graft chain poly(MOVE); with no signals attributable to other structures. According to the MWD and structural analysis, the coupling reaction proceeds without any side reactions, affording PVAc graft copolymers with structure 2 in Scheme 1; the product polymers were free of homopoly(MOVE).

We also examined the coupling reaction with poly(vinyl ether)s having various alkoxyl or alkyl side groups; poly(EOVE), poly(BOVE), and poly(IBVE), which are know to have significantly different properties from those of poly(MOVE). The graft efficiency in these experiments was clearly affected by the structure of monomer side groups, as shown in Figure 5. Under the optimum conditions for poly(MOVE), the graft efficiency was seen to decrease as follows: the graft efficiency of poly(MOVE) was 100\%; poly(EOVE), $93 \%$; 


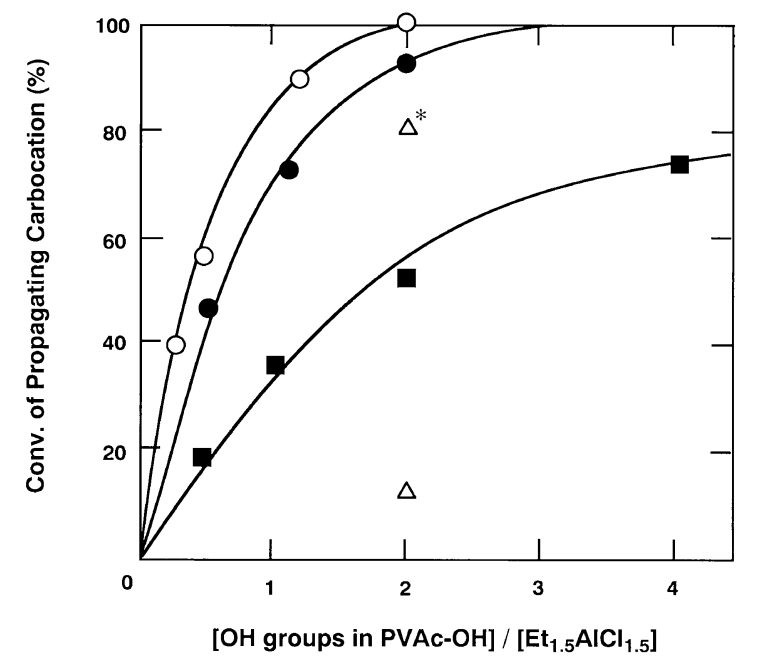

Figure 5. Relationships between [OH groups in PVAc-OH] / $\left[\mathrm{Et}_{1.5} \mathrm{AlCl}_{1.5}\right]$ and conversion of the propagating species obtained by polymerization of vinyl ethers with $\mathbf{1} / \mathrm{Et}_{1.5} \mathrm{AlCl}_{1.5}$ initiating system in the presence of ethyl acetate in toluene at $0^{\circ} \mathrm{C}$. Vinyl ethers: $(\bigcirc)$ MOVE, $(\bigcirc)$ EOVE, $(\boldsymbol{\square})$ BOVE, $(\triangle)$ IBVE, $\left(\triangle^{*}\right) \operatorname{IBVE}(+$ addition of a small amount of MOVE at the end of IBVE polymerization): $[\text { vinyl ether }]_{0}=0.44 \mathrm{M},[1]_{0}=4.0 \mathrm{mM},\left[\mathrm{Et}_{1.5} \mathrm{AlCl}_{1.5}\right]_{0}=20 \mathrm{mM}$, $[$ ethyl acetate $]=1.0 \mathrm{M}$.

and poly(BOVE), 53\% . The steric hindrance of side groups and the incompatibility between the polymer reagents were thought to cause the decrease of graft efficiency. In the case of less reactive poly(IBVE) propagating species, the coupling reaction proceeded only marginally, giving graft copolymers in only $14 \%$ yield. The addition of a small amount of more reactive monomers at the end of IBVE polymerization was found to be effective in increasing graft efficiency. For example, a drastic increase in the graft efficiency of poly(IBVE), from $14 \%$ to $80 \%$, was observed using MOVE as the added reactive monomer.

To prepare copolymers with different graft segments such as AB-or BA-blocks, random, gradient, and two kinds of graft chains, further experiments were carried out using various living polymerization techniques, as shown in Scheme 2. In a forthcoming report, we will present and discuss the methods of preparation and the characteristic properties. As an example of the findings, the properties of graft copolymers with AB-block grafts were found to be considerably different from those with BA-block or random grafts etc., despite having the same composition ratios, molecular weights, and narrow MWDs of grafts.

\section{Synthesis and Properties of PVA Graft Copolymers}

The hydrolysis of PVAc-graft-poly(vinyl ether)s gives poly(vinyl alcohol) derivatives; PVA-graftpoly(vinyl ether)s. The PVAc graft copolymer was hydrolyzed in $1 \mathrm{wt} \% \mathrm{NaOH}$ aqueous solution at room
(A)

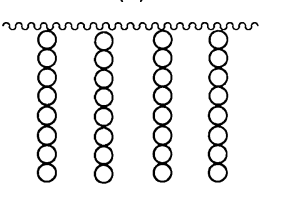

(D)

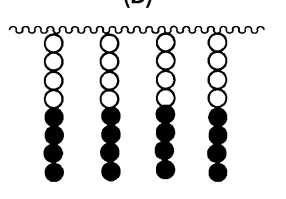

Scheme 2. PVA graft copolymers with different graft segments.

temperature for $24 \mathrm{~h}$. The quantitative progress of hydrolysis was confirmed by ${ }^{1} \mathrm{H}$ NMR and IR measurements. Upon hydrolysis, the IR absorption peak of the ester side group $\left(v_{\mathrm{C}=\mathrm{O}}, 1736 \mathrm{~cm}^{-1} ; v_{\mathrm{C}-\mathrm{O}}, 1248 \mathrm{~cm}^{-1}\right)$ disappeared completely, and a broad signal attributable to hydroxyl groups $\left(v_{\mathrm{OH}}, 3450 \mathrm{~cm}^{-1}\right)$ appeared. The products gave the ${ }^{1} \mathrm{H}$ NMR spectra expected for PVAgraft-poly(MOVE): $\delta\left(\mathrm{ppm}\right.$, in $\left.\mathrm{D}_{2} \mathrm{O}\right) ; 1.5-1.8(\mathrm{~m}$, $\left.-\mathrm{CH}_{2}-\right), 3.4\left(\mathrm{~s},-\mathrm{O}-\mathrm{CH}_{3}\right), 3.5-3.8(\mathrm{~m},-\mathrm{CH}-\mathrm{O}-\mathrm{C}$ and $\left.-\mathrm{CH}_{2}-\mathrm{O}-\right)$, and $3.9-4.1(\mathrm{~m},-\mathrm{C} \underline{\mathrm{H}}-\mathrm{OH})$. The spectral analysis verified the quantitative removal of acetoxyl groups from PVAc-graft-poly(vinyl ether)s and the formation of PVA-graft-poly(vinyl ether)s having a PVA main chain and poly(vinyl ether)s in the graft chain. To examine the stability of the graft copolymers containing acetal linkage, the aqueous solutions $(2 \mathrm{wt} \%)$ of graft copolymers were allowed to stand for $24 \mathrm{~h}$ under mild acidic conditions ( $\mathrm{pH} 5$ ) at room temperature. The quantitative recovery of graft copolymers was confirmed by spectroscopic measurements and extraction experiments, indicating the moderate stability of the acetal linkage. Further, no decomposition of copolymers took place during storage either in bulk or in solution for several months and during the film casting at varied temperature.

The resulting PVA graft copolymers were soluble in many organic solvents and water at room temperature. In Table I, the solubility characteristics of PVA-graftpoly(vinyl ether)s are compared with those of graft chains and related polymers. PVA-graft-poly(vinyl ether)s completely differ in solubility to PVA; PVAgraft-poly(MOVE) was soluble in both non-solvents for PVA (toluene, chloroform etc.) and good solvents for PVA (water, DMSO) at room temperature.

We also investigated the unique water solubility behavior of the PVA graft copolymers at various temperatures, as graft segments of poly(MOVE) or poly(EOVE) are known to exhibit thermosensitive phase separation in water. ${ }^{15,16}$ As shown in Table II and Figure 6, PVA-graft-poly(MOVE) was clearly soluble 
Table I. Solubility ${ }^{\mathrm{a}}$ of various PVA graft copolymers ${ }^{\mathrm{b}}$ at room temperature (5 $\left.\mathrm{wt} \%\right)$

\begin{tabular}{|c|c|c|c|c|c|}
\hline & toluene & $\mathrm{CHCl}_{3}$ & $\mathrm{CH}_{3} \mathrm{OH}$ & $\mathrm{H}_{2} \mathrm{O}$ & DMSO \\
\hline Poly(MOVE) & O & $\bigcirc$ & O & O & O \\
\hline PVA-graft-poly(MOVE) (A) ${ }^{d}$ & $x$ & $\triangle$ & $x$ & $\bigcirc$ & $\bigcirc$ \\
\hline PVA-graft-poly(MOVE) (B) ${ }^{\mathrm{d}}$ & $\triangle$ & $\bigcirc$ & $x$ & $\bigcirc$ & $\bigcirc$ \\
\hline PVA-graft-poly(MOVE) (C) ${ }^{\mathrm{d}}$ & $\bigcirc$ & $\bigcirc$ & $\triangle$ & $\bigcirc$ & $\bigcirc$ \\
\hline Poly(EOVE) & $\bigcirc$ & $\bigcirc$ & $\bigcirc$ & $x^{c}$ & $\bigcirc$ \\
\hline PVA-graft-poly(EOVE) & $x$ & $\bigcirc$ & $x$ & $x^{c}$ & $\bigcirc$ \\
\hline Poly(BOVE) & $\bigcirc$ & $\bigcirc$ & $\bigcirc$ & $x$ & $x$ \\
\hline PVA-graft-poly(BOVE) & $x$ & $x$ & $x$ & $x$ & $\bigcirc$ \\
\hline PVA & $x$ & $x$ & $x$ & $\bigcirc$ & $\bigcirc$ \\
\hline PVAc-OH & $\bigcirc$ & $\bigcirc$ & $\bigcirc$ & $x$ & $\bigcirc$ \\
\hline PVAc-graft-poly(MOVE) & $\bigcirc$ & $\bigcirc$ & $\bigcirc$ & $x$ & $\bigcirc$ \\
\hline
\end{tabular}

Table II. Aqueous solution behavior ${ }^{\mathrm{a}}$ of PVA graft copolymers ${ }^{\mathrm{b}}$ at various temperatures $(5 \mathrm{wt} \%)$

\begin{tabular}{lccccc}
\hline & Ratio of segments & \multicolumn{4}{c}{ Solubility } \\
\cline { 4 - 6 } & PVA/poly(MOVE) & $0^{\circ} \mathrm{C}$ & $25^{\circ} \mathrm{C}$ & $40^{\circ} \mathrm{C}$ & $70^{\circ} \mathrm{C}$ \\
\hline PVA-graft-poly(MOVE) & $3 / 2$ & $\triangle$ & $\bigcirc$ & $\bigcirc$ & $\times$ \\
$\overline{D P}_{\mathrm{n}}: 500$ & $1 / 1$ & $\triangle$ & $\bigcirc$ & $\bigcirc$ & $\times$ \\
180 & $1 / 2$ & $\bigcirc$ & $\bigcirc$ & $\bigcirc$ & $\times$ \\
180 & $1 / 0$ & $\triangle$ & $\bigcirc^{\mathrm{c}}$ & $\bigcirc$ & $\bigcirc$ \\
PVA & $0 / 1$ & $\bigcirc$ & $\bigcirc$ & $\bigcirc$ & $\times$ \\
Poly(MOVE) & & & & \\
\hline
\end{tabular}

${ }^{\mathrm{a}} \bigcirc$ : soluble, $X$ : phase separation, and $\triangle$ : partly gelation. ${ }^{\mathrm{b}}$ Polymerization conditions: $[\text { monomer }]_{0}=0.44 \mathrm{M},[\mathbf{1}]=4.0 \mathrm{mM},\left[\mathrm{Et}_{1.5} \mathrm{AlCl}_{1.5}\right]_{0}=20 \mathrm{mM}$, [ethyl acetate $=1.0 \mathrm{M}$, in toluene at $0^{\circ} \mathrm{C}$; PVAc-OH: $\overline{\mathrm{DP}}_{\mathrm{n}}=250$, saponification value $=10 \%$. ${ }^{\mathrm{c}}$ Partly gelation on standing for long time.

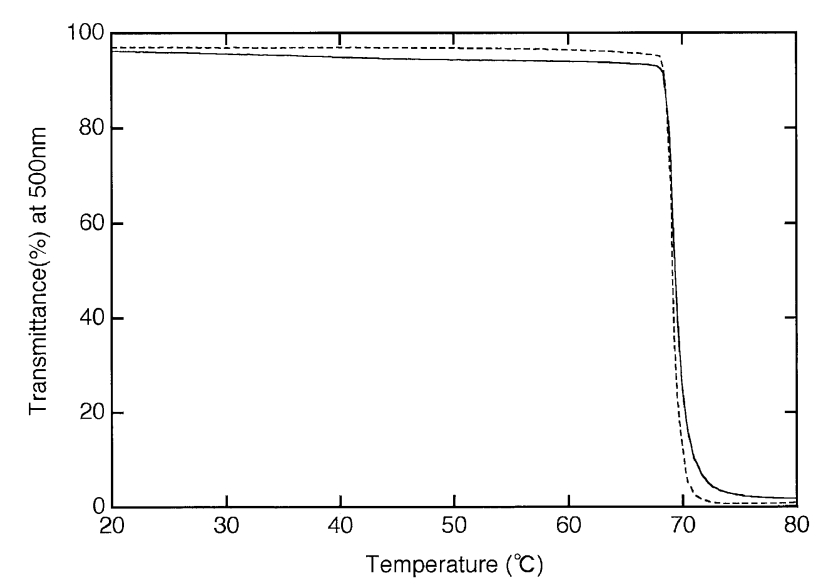

Figure 6. UV diagram, traced by the transmittance with a $500-\mathrm{nm}$ light beam, of $0.5 \mathrm{wt} \%$ aqueous solution of PVA-graftpoly(MOVE); heating or cooling rate: $1^{\circ} \mathrm{C} \mathrm{min}^{-1}$, heating up (-) and cooling down (---).

in water at room temperature. When the solution was warmed to $70^{\circ} \mathrm{C}$, the clear solution changed to opaque in a rapid transition. The phase separation was found to be very sensitive and reversible on heating or cooling. The thermosensitive behavior of poly(MOVE) segments is thought to occur due to the dehydration of segments above a critical temperature. ${ }^{15,16}$ On the other hand, when the solution was maintained at below room temperature, insoluble components began to fall out of solution. This phenomenon is thought to be attributable to the physical gelation of PVA main chains. Therefore, the covalently connected structure of two characteristic segments independently produced such unique solution behavior in water. In a forthcoming paper, we will discuss micelle formation in several solvents and the solubility behavior of other graft copolymers having different graft segments.

The film formation property of PVA graft copolymers was preliminarily examined using PVA-graftpoly $(\mathrm{MOVE})\left[\mathrm{PVA} /\right.$ poly $(\mathrm{MOVE})=3 / 2, \overline{\mathrm{DP}}_{\mathrm{n}}(\mathrm{PVA})=$ $500, \bar{M}_{\mathrm{n}}$ of poly(MOVE): $\left.7.4 \times 10^{3}\right]$. The graft copolymer was dissolved in water to form $c a$. $10 \mathrm{wt} \%$ polymer solution and cast into film on a polyethylene plate 


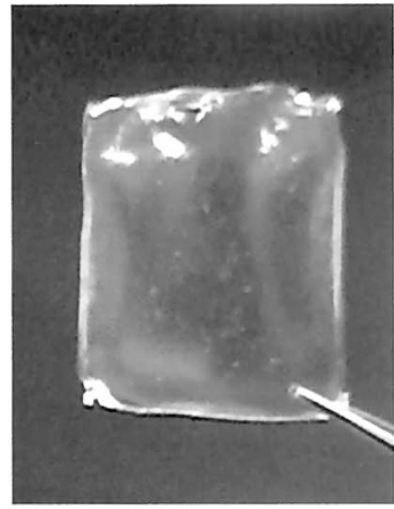

(A)

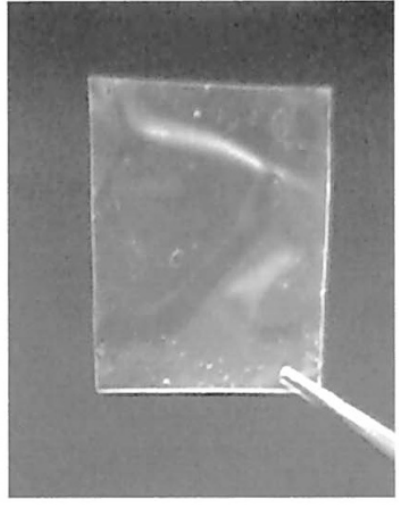

(B)

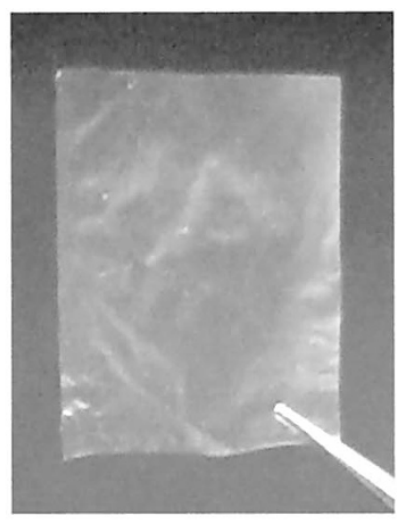

(C)

Figure 7. Films obtained from (A) PVA, (B) the mixture of PVA-graft-poly(MOVE) with PVA (40/60, wt\%), and (C) PVA-graftpoly(MOVE).

at room temperature by slowly removing the solvent over 3 days. To complete solvent removal, the film was vacuum-dried $(1 \mathrm{mmHg})$ at room temperature for $12 \mathrm{~h}$. Figure 7 shows the films obtained from PVA-graftpoly(MOVE) alone and from its mixture with PVA $(40 / 60, w t \%)$. The films obtained from the mixture of PVA and its graft copolymer were almost transparent and relatively tough, whereas a translucent film was obtained from the graft copolymer alone. The physical properties and microstructure of the cast film are currently under investigation.

\section{REFERENCES}

1. L. Zhang and A. Eisenberg, Science, 268, 1728 (1995).

2. K. Schillen, K. Bryskhe, and Y. S. Mel'nikova, Macromolecules, 32, 6885 (1999).

3. J. J. L. M. Cornelissen, M. Fischer, N. A. J. M. Sommerdijk, and R. J. M. Nolte, Science, 280, 1427 (1998).

4. H. Huang, T. Kowalewski, E. E. Remsen, R. Gertzmann, and K. L. Wooly, J. Am. Chem. Soc., 119, 11653 (1997).

5. Y.-Y. Won, H. T. Davis, and F. S. Bates, Science, 283, 960 (1999).

6. D. Mardare and K. Matyjaszewski, Macromolecules, 27, 645 (1994).

7. D. White and K. Matyjaszewski, J. Macromol., Sci., Pure Appl. Chem., A34, 221 (1997).

8. E. Rizzardo, J. Chiefari, R. T. A. Mayadunne, G. Moad, and S. H. Thang, 'Synthesis of Defined Polymers by Reversible Addition-Fragmentation Chain Transfer (The Raft Process)' in "Controlled/Living Radical Polymerization -Progress in ATRP, NMP and RAFT-”, K. Matyjaszewski, Ed., ACS Symp. Ser., Oxford, 2000, vol. 768, p 278.

9. Y. Kawakami, T. Aoki, and Y. Yamashita, Polym. Bull., 18, 473 (1987).

10. T. Fukutomi and K. Ishizu, J. Polym. Sci., Part C, 25, 175 (1987).

11. Y. Tezuka, A. Fukushima, S. Matsui, and K. Imai, J. Colloid Interface Sci., 114, 16 (1987).

12. Y. Tezuka and A. Araki, Makromol. Chem., 194, 2827 (1993).

13. T. Ohnaga and T. Sato, Polymer, 37, 3729 (1996).

14. S. Aoshima and T. Higashimura, Macromolecules, 22, 1009 (1989).

15. S. Aoshima, H. Oda, and E. Kobayashi, J. Polym. Sci., Part A: Polym. Chem., 30, 2407 (1992).

16. S. Aoshima and E. Kobayashi, Macromol. Symp., 95, 91 (1995).

17. S. Aoshima and S. Sugihara, J. Polym. Sci., Part A: Polym. Chem., 38, 3962 (2000).

18. S. Aoshima and K. Hashimoto, J. Polym. Sci., Part A: Polym. Chem., 39, 746 (2001).

19. As a review, see: P. F. Rempp and P. J. Lutz, 'Synthesis of Graft Copolymers' in "Comprehensive Polymer Science", S. G. Allen and J. C. Bevington, Ed., Pergamon Press, Oxford, 1989, vol. 6, p 403.

20. S. Aoshima, M. Ikeda, and E. Kobayashi, Polym. Preprs. Jpn., 47, 256 (1998); S. Aoshima, K. Nakayama, and M. Ikeda, Polym. Preprs. Jpn., 48, 1155 (1999); S. Aoshima, K. Nakayama, and N. Sato, Polym. Preprs. Jpn., 49, 380 (2000).

21. For a part 2 of this series; S. Aoshima, Y. Segawa, and Y. Okada, J. Polym. Sci., Part A: Polym. Chem., 39, 751 (2001). 